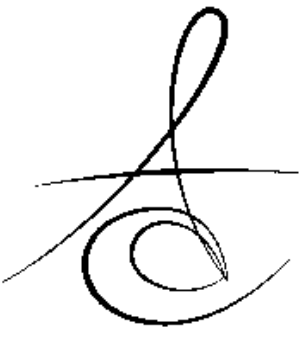

Makale Kodu/Article code: 2710

Makale Gönderilme tarihi: 24.03.2016

Kabul Tarihi; 23.06..2016

\section{TAM PROTEZ YAPIMINDA TEORİK VE PRATİK EĞİTIMİN SÜBJEKTİF DEĞERLENDİRİLMESİ}

\section{SUBJECTIVE EVALUATION OF THE THEORETICAL AND PRACTICAL EDUCATION IN COMPLETE DENTURE}

\author{
Doç. Dr. Ş. Begüm TÜRKER**
}

\section{ÖZET}

Amaç: Çalışmanın amacı, pratik eğitim veya teorik pratik eğitim alan diş hekimliği öğrencilerinin tam protez yapımı sırasındaki sübjektif düşüncelerinin değerlendirilmesi ve karşılaştııılmasıdır.

Materyal ve Metod: Çalışmaya toplam 85 adet 5. Sınıf öğrencisi katılmıştır. 5. Sınıf öğrencileri 3. Sınıfta iken sadece pratik eğitim ile tam protez yapmışlar ve hastalara uygulamışlardır. Aynı öğrenciler 5. Sınıfta teorik eğitimlerini tamamladıktan sonra tam protez yapmışlardır. Pratik ve teorik eğitimin belirlenmesi amacı ile 22 soruluk anket hazırlanmıştır. Ankette öğrencilere pratik ve pratikteorik eğitim hakkındaki düşünceleri, tam protez yapımı sırasında karşılaşılan problemler, yapılan protezlerden hasta ve hekim memnuniyetini içeren sorular hazırlanmıştır. Anket 85 adet 5. Sınıf öğrencisi tarafından cevaplandırılmıştır. Sonuçların analizi tanımsal istatistiklerden yüzdelik frekanslarla yapılmıştır.

Bulgular: Ankete katılan öğrencilerin \%100'ü tam protezde başarı sağlamak için teorik ve pratik bilginin şart olduğunu belirtmiştir. Ankete katılan öğrencilerin $\% 64,7$ 'si tam protezlerin başarısının hekim tecrübesine ve doğru teknik uygulamaya bağlı olduğunu bildirmişlerdir. Genel olarak, öğrenciler kendilerini 5. Sınıfta tam protezi yaparken daha başarılı ve 3. Sınıf iken kaygı ve kendine güvensizlik hissetmişlerdir. Öğrenciler, 5. Sınıfta tam protez yaparlarken daha az zaman ve materyal harcamışlardır. Öğrencilerin \% 84.7’si 3. Sınıfta pratik eğitim ile tam protez yapmaktan mutlu olduklarını ve yine $\% 91.8^{\prime}$ i 3. Sınıfta pratik eğitim yapmasalardı, teorik eğitimlerini tamamladıktan sonra yaptıkları tam protezde başarılı olamayacaklarını bildirmişlerdir.

Sonuç: 5. Sınıf öğrencileri teorik eğitimin tamamlanıp pratik uygulamaya geçilmesinin en verimli öğrenme şekli olduğunu bildirmişlerdir.

Anahtar Kelime: Teorik eğitim, pratik eğitim, tam protez yapımı

\section{ABSTRACT}

Aim: The purpose of this article was to evaluate and to compare the subjective assessment of theoretical and practical education in complete denture.

Materials and Methods: A total of 85 Marmara University Faculty of Dentistry Grade5 students were participated to the study. Grade 5's tudents was made complete denture in the clinic when they were in Grade 3 with practical education and in Grade 5 after achieving their theoretical program. A questionnaire with 22 questions, including the subjective assessment of theoretical and practical education, problems that they were encountered during the construction of complete denture and satisfaction of patients and students was prepared. Questionnaires were filled by 85 's Grade 5 students. Results were determined by percentiles. Results: Survey showed that $100 \%$ of the students reported that to construct successful complete denture the theoretical and practical education was important. $64.7 \%$ of the students were thought that the denture satisfaction was related to the dentist's experience and using adequate technique and material. Generally, the students have more satisfied during the construction of the complete denture at Grade 5 and were felt anxiety and lack of self-confidence in the clinic when they were in Grade 3. Students were spending less time and less material for making complete denture when they were at Grade $5.84 .7 \%$ of the students were satisfied making complete denture with practical education when they were in Grade 3 and also $91.8 \%$ of the students was reported that if they had not to do practical education at the Grade 3, they will not to do complete denture as well as after achieving their theoretical education.

Conclusıon: Grade 5 students were reported that the most efficient way of learning is to make practical practice after achieving the theoretical education during making complete denture.

Key-Words: Theoretical education, practical education, construction of complete denture

\footnotetext{
*., Bezmialem Üniversitesi Diş Hekimliği Fakültesi, Ağız, Diş ve Çene Cerrahisi AD

${ }^{* *}$ Marmara Üniversitesi Diş Hekimliği Fakültesi, Protetik Diş Tedavisi $A D$
} 


\section{GİRIŞ}

Başarılı bir tam protez için hasta, hekim ve teknisyene bağı birtakım faktörler vardır. Diş hekimi ağız anatomisi ve fizyolojisi hakkında bilgili, protez yapımı konusunda deneyimli ve insan ilişkilerini bilen bir kişi olmalıdır ${ }^{1}$. Davies ve ark ${ }^{2}$. tam protez yapımının bir işlemler dizisi olduğunu ve her bir işlemin birbirini etkilediğini ve "EDEC" prensibinin takip edilmesi gerektiğini söyler. E: Examine (Muayene), D:Design (Tasarım), E:Execute (Yürürlüğe koyma, uygulama), C:Check (Kontrol).

Tam protez yapımında bir çok işlem sırası ile yapılmalıdır. Tedavi, dişsiz hastanın anamnezinin alınmasi $^{3,4}$, klinik ve radyografik değerlendirme ile başlar $^{1,3}$ ve 1.ölçü, 2. ölçü alımı ${ }^{1,3,5-9}$, okluzal mum duvarların hazırlanması ${ }^{7,10}$, dikey boyutun saptanma$\mathrm{SI}^{1,3,11-13}$, sentrik ilişki tespi ${ }^{3,5,12-17}$, kayıtların artikülatöre transferi ${ }^{1,3,5,18-26}$, diş seçimi, diş dizimi ve dişli provadan $^{1,3,27-30}$ sonra sıcak akril tepimi, tesviye ve cila işlemleri ${ }^{1,3}$, tam protezlerin elde edilmesi, protezlerin hastaya uygulanması ve uyumlandırılması ile tamamlanır.

Tam protezlerin yapım aşamalarının öğretilmesi iki etaplı yapılmaktadır. Birinci etap, yazılı, sözlü eğitimleri, ders içeriklerinde sıklıkla kullanılan vaka sunumlarını içeren teorik eğitim; ikinci etap ise laboratuvar ve klinik çalışma zamanlarını ve klinikte hasta başında yapılan demonstrasyonları içeren pratik eğitimdir. Başarılı bir tam protez yapabilmek için, anamnez aşamasından başlanarak çalışma prensiplerinin tam ve doğru uygulanması gerekmektedir. Alınan eğitim çok önemlidir. Teorik ve pratik eğitimin eksiksiz olması gerekmektedir. Çalışmanın amacı, pratik veya teorik-pratik eğitim alan diş hekimliği öğrencilerinin tam protez yapımı sırasındaki sübjektif düşüncelerinin değerlendirilmesi ve karşılaştırılmasıdır.

\section{GEREÇ VE YÖNTEM}

Çalışmamız Marmara Üniversitesi Diş Hekimliği Fakültesi Protetik Diş Tedavisi AB'da yapılmıştır. Pratik ve teorik eğitimin belirlenmesi amacı ile bir anket hazırlanmıştır. Ankete 85 adet 5. Sınıf öğrencisi katılmıştır. Tam protez preklinik eğitimini tamamlamış 5 . Sınıf öğrencileri 3. Sınıfta iken, 6 asistan ve 1 öğretim üyesi eşliğinde sadece pratik eğitim ile tam protez yapmışlar ve hastalara uygulamışlardır. Aynı öğrenciler
5. Sınıfta teorik eğitimlerini tamamladıktan sonra yine 6 asistan ve 1 öğretim üyesi eşliğinde tam protez yapmışlardır. Öğrencilere pratik ve pratik-teorik eğitim hakkındaki düşünceleri, tam protez yapımı sırasında karşılaşılan problemler, yapılan protezlerden hasta ve hekim memnuniyetini içeren 22 adet soru sorulmuştur (Tablo 1). Cevaplar genellikle evet hayır olarak hazırlanmış ve. 9. Soruda öğrencilerin pratik ve teorik eğ timle ilgili düşünceleri istenmiştir. Çalışmada elde edilen bulgular değerlendirilirken, istatistiksel analizler için SPSS (Statistical Package for Social Sciences)Windows 17.0 programı kullanılmıştır. Çalışma verileri tanımlayıcı istatistiksel metotlardan yüzdelik frekanslarla hesaplanmıştır.

\section{Tablo 1: Anket Soruları \\ TAM PROTEZ YAPIMINDA TEORİK VE PRATIK EĞITIMIN ÖNEMI}

3.sınıfta pratik bilgi ile ve 5. Sınıfta teorik+pratik bilgi ile yaptığımız tam protezler için hazırlanan ankettir.

İlginize teşekkür ederim.

1-Tam proteze teorik bilgiye sahip olunarak başlamak sizce başarı sağlamak için yeterli mi?

a)Tam protez yapabilmek için sadece teorik bilgi yeterlidir.

b)Sadece pratik bilgi yeterlidir.

c)Teorik ve pratik bilgi şarttır.

2- 3.sınıfta tam protezi ilk yaptığınızda ölçü alırken uyguladığınız ağız hareketlerinin amacını biliyor muydunuz?

a)Evet b)Hayır

3- 3.sınıfta tam protezde 1. ölçü alırken ölçünün doğru alınıp alınmadığına karar verebildiniz mi?

a)Evet b) Hayır

5. sınıfta tam protezde 1 . ölçü alırken ölçünün doğru alınıp alınmadığına karar verebildiniz mi?

a)Evet b)Hayır

4- 3. sınıfta tam protezde 2. ölçü alırken ölçünün doğru alınıp alınmadığına karar verebildiniz mi?

a)Evet b) Hayır

5. sınıfta tam protezde 2 . ölçü alırken ölçünün doğru alınıp alınmadığına karar verebildiniz mi?

a)Evet b)Hayır

5- 3. Sınıfta tam protezde mum duvarlar ile okluzal düzlem ve dikey boyutu doğru tespit edebildiniz mi?

a)Evet b)Hayır

5.Sınıfta tam protezde mum duvarlar ile okluzal düzlem ve dikey boyutu doğru tespit edebildiniz $\mathrm{mi}$ ?

a)Evet b)Hayır

6-3.sınıfta tam protezde dişli prova için ne kadar zaman harcadınız?

a) 1 seans

b) 2 seans

c) 3 seans

d) 4 ve daha fazla seans

5.sınıfta tam protezde dişli prova için ne kadar zaman harcadınız?

a) 1 seans

b) 2 seans

c) 3 seans

d) 4 ve daha fazla seans

7- 3.sınıfta tam protezin uyumlandırılmasında zorlandınız mı?

a)Evet b) Hayır

5.sınıfta tam protezin uyumlandırılmasında zorlandınız mı?

a)Evet b)Hayır

8-Sizce 3. sınıfta iken tam protez yapmak sizin eğitiminize katkı sağladı mı?

a)Evet b)Hayır 


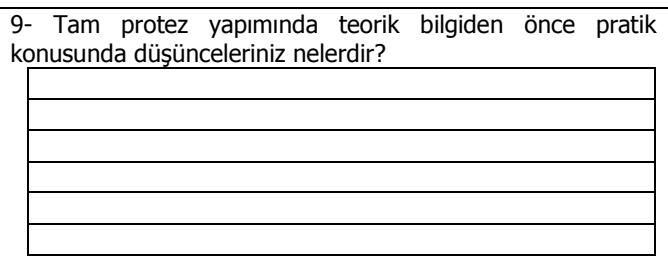

10- 3. ve 5. sınıfta tam protez yapımına ayırdığınız seans sayısında veya saatte farklılık oldu mu?

a)Evet b)Hayır

11-3. ve 5. sınıfta tam protez yaparken kullandığınız malzeme miktarında farklılık oldu mu?

a)Evet b)Hayır

12-Teorik bilgi tam veya eksik iken, sizden daha deneyimli hekimi izleyerek tam protez yapımını anlayabildiniz mi?

a)Teorik bilgim eksik iken görsel anlatım ile tedavi basamaklarını tam olarak anladım

- Evet Hayır

b)Teorik bilgim eksik iken görsel anlatım ile tedavi basamakların tam olarak anlayamadım, pratik yaptığım zaman anladım

- Evet Hayır

c)Teorik bilgim tam pratik bilgim var iken görsel anlatım ile tedavi basamaklarını tam olarak anlayamadım

- Evet Hayır

d)Pratik bilgim tam teorik bilgim yok iken sözlü anlatım ile tedavi basamaklarını anladım

- Evet Hayır

13-Pratik uygulama yapmamış olsaydınız derslerde öğretilen teorik bilgiden sonra tam protezi tek başınıza yapmak zorunda olsaydınız, başarılı olabilir miydiniz?

a)Evet b) Hayır

14-Öğrencilik hayatınız boyunca görülen vaka sayısı kısıtı olduğundan, mezun olduktan sonra karşılaşabilinecek farklı problemlerde teorik bilginize dayanarak doğru tedavi planı yapabileceğinizi düşünüyor musunuz?

a)Evet b)Hayır

15-3. sınıfta yaptığınız tam protezden hastalar yeterince memnun kaldı mı?

a)Evet b)Hayır

**Hayır ise ne gibi şikayetlerle geri döndüler?

Protezin ağızda durmaması

Yemek sırasında kullanamama

Vuruk şikayetler

Eklem rahatsızlıklar

5.sınıfta yaptığınız tam protezden hastalar yeterince memnun kaldı mı?

a)Evet b)Hayır

**Hayır ise ne gibi şikayetlerle geri döndüler?

Protezin ağızda durmamas

Yemek sırasında kullanamama

Vuruk şikayetleri

Eklem rahatsızlıkları

16-Tam protezlerin başarısı size göre;

a)Hekim tecrübesine ve doğru teknik uygulamaya bağlıdır

b) Hekim tecrübesine bağlıdır

c)Doğru malzeme kullanımına bağlıdır

d)Doğru teknik ve doğru malzeme kullanımına bağlıdır

17-Yaptığınız her iki total protezden de memnun kaldınız mı?

a)İki protezde de başarı sağlayabildim

b)Tecrübesiz olduğum ilk protez başarısızdı, ikinci protezimde başarı yakalayabildim

c) İki protezde de başarı yakalayamadım.

**Başarısız olduysanız bunu neye bağlıyorsunuz

- Vakanın zorluğu

Bilgi ve deneyim eksikliğ

Deneyim eksikliği

Bilgi eksikliği

18-Dişli prova esnasında dikkat etmeniz gerekenleri teorik olarak bildiğiniz halde bunu pratikte uygulayabildiniz mi?

a)Evet b)Hayır
19- 5. sınıfta tam protez yaparken her aşamada sizden daha tecrübeli birinin onayına gerek duydunuz mu?

a)Evet b)Hayır

Ya da kendiniz doğru yaptığınıza karar verebildiniz mi?

a)Evet

b)Hayı

20-Sizce teorik bilgiler her vakada aynen geçerli olmak zorunda $\mathrm{mI}$ ? a)Evet b)Hayır

Pratikte vakaya göre değişiklik yapmak gerekebiliyor mu? a)Evet b)Hayır

21- 5. sınıfta preprotetik tedavinin nasıl yapılacağını biliyor muydunuz?

a)Evet b)Hayır

22- 3. sınıfta tam protez hastasının panaromik filmini tanımlayabildinizi mi?

a)Evet b)Hayır

5. sınıfta tam protez hastasının panaromik filmini tanımlayabildinizi $\mathrm{mi}$ ?

a)Evet

b)Hayır

\section{BULGULAR}

Anket sonuçlarının yüzdelik frekans analizi Tablo $2^{\prime}$ de gösterilmektedir. Ankete katılan öğrencilerin $\% 100$ 'ü tam protezde başarı sağlamak için teorik ve pratik bilginin şart olduğunu belirtmiştir. 3. Sınıfta yapılan tam protez çalışması sırasında öğrencilerin bilgi eksikliğinden kaynaklanan kaygı ve kendine güvensizlik ön planda olduğu tespit edilmiştir.

Ankete katılan öğrencilerin \%63, $5^{\prime} \mathrm{i}$ 3.Sınıfta tam protezi ilk yaptığında ölçü alırken uyguladığı ağız hareketlerinin amacını bildiğini, \%36,5'i bilmediğini belirtmiştir.

Ankete katılan öğrencilerin \%20si 3.Sınıfta tam protezde 1. ölçü alırken ölçünün doğru alınıp alınmadığına karar verebildiğini, \%80'i karar veremediğini belirtmiştir. Ankete katılan öğrencilerin \%89,4'ü 5.Sınıfta tam protezde 1. ölçü alırken ölçünün doğru alınıp alınmadığına karar verebildiğini, \%10,6'sı karar veremediğini belirtmiştir.

Ankete katılan öğrencilerin \%14,1'i 3.Sınıfta tam protezde 2. ölçü alırken ölçünün doğru alınıp alınmadığına karar verebildiğini, \%84,7'si karar vereme diğini belirtmiştir. Ankete katılan öğrencilerin $\% 89,4$ 'ü 5.Sınıfta tam protezde 2. ölçü alırken ölçünün doğru alınıp alınmadığına karar verebildiğini, \%10,6'sı karar veremediğini belirtmiştir

Ankete katılan öğrencilerin $\% 44,7$ 'si 3 . Sınıfta tam protezde mum duvarlar ile okluzal düzlem ve dikey boyutu doğru tespit edebildiğini, \%55,3'ü doğru tespit edemediğini belirtmiştir. Ankete katılan öğrencilerin $\% 87,1^{\prime}$ i 5 .Sinffta tam protezde mum duvarlar ile okluzal düzlem ve dikey boyutu doğru tespit edebildiğini, \%12,9'u doğru tespit edemediğini belirtmiştir.

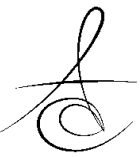




\begin{tabular}{|c|c|c|c|}
\hline & & $\mathbf{N}$ & $\%$ \\
\hline \multirow[t]{3}{*}{ Soru 1} & Sadece teorik bilgi & 0 & 0 \\
\hline & Sadece pratik bilgi & $\mathbf{0}$ & $\mathbf{0}$ \\
\hline & Teorik ve pratik bilgi & 85 & 100 \\
\hline \multirow{2}{*}{ Soru 2} & Evet & 54 & 63,5 \\
\hline & & 31 & 36,5 \\
\hline \multirow{2}{*}{ Soru 3a } & Evet & 17 & 20 \\
\hline & Hayır & 68 & 80 \\
\hline \multirow[t]{2}{*}{ Soru 3b } & Evet & 76 & 89,4 \\
\hline & & 9 & 10,6 \\
\hline \multirow[t]{2}{*}{ Soru 4a } & Evet & 12 & 14,1 \\
\hline & Hayır & 72 & 84,7 \\
\hline \multirow[t]{2}{*}{ Soru 5a } & Evet & 38 & 44,7 \\
\hline & Hayır & 47 & 55,3 \\
\hline \multirow[t]{2}{*}{ Soru $\mathbf{5 b}$} & Evet & 74 & 87,1 \\
\hline & Hayır & 11 & 12,9 \\
\hline \multirow[t]{4}{*}{ Soru 6a } & 1 seans & 4 & 4,7 \\
\hline & 2 seans & 10 & 11,8 \\
\hline & 3 seans & 18 & 21,2 \\
\hline & 4 ve daha fazla seans & 53 & 62,4 \\
\hline \multirow[t]{4}{*}{ Soru 6b } & 1 seans & 14 & 16,5 \\
\hline & 2 seans & 27 & 31,8 \\
\hline & 3 seans & 18 & 21,2 \\
\hline & 4 ve daha fazla seans & 26 & 30,6 \\
\hline \multirow[t]{2}{*}{ Soru 7a } & Evet & 54 & 63,5 \\
\hline & Hayır & 31 & 36,5 \\
\hline \multirow[t]{2}{*}{ Soru $\mathbf{7 b}$} & Evet & 29 & 34,1 \\
\hline & Hayır & 56 & 65,9 \\
\hline \multirow[t]{2}{*}{ Soru 8} & Evet & 72 & 84,7 \\
\hline & Hayır & 13 & 15,3 \\
\hline Soru 9 & Olumlu & 83 & 96,4 \\
\hline & Olumsuz & 2 & 3,6 \\
\hline Soru 10 & Evet & 71 & 83,5 \\
\hline & Hayır & 14 & 16,5 \\
\hline Soru 11 & Evet & 67 & 78,8 \\
\hline & Hayır & 18 & 21,2 \\
\hline Soru 12a & Evet & 29 & 33,7 \\
\hline & Hayır & 47 & 54,7 \\
\hline Soru 12b & Evet & 70 & 81,4 \\
\hline & Hayır & 8 & 9,3 \\
\hline Soru $12 c$ & Evet & 10 & 11,6 \\
\hline & Hayır & 54 & 62,8 \\
\hline Soru 12d & Evet & 26 & 30,2 \\
\hline & Hayır & 37 & 43 \\
\hline Soru 13 & Evet & 7 & 8,2 \\
\hline & Hayır & 78 & 91,8 \\
\hline Soru 14 & Evet & 26 & 30,6 \\
\hline & Hayır & 59 & 69,4 \\
\hline Soru 15a & Evet & 59 & 69,4 \\
\hline & Hayır & 26 & 30,6 \\
\hline Soru 15b & Evet & 68 & 80 \\
\hline & Hayır & 17 & 20 \\
\hline Soru 16 & Hekim tecrübesi ve & & \\
\hline & doğru teknik & 55 & 64,7 \\
\hline & Hekim tecrübesi & 3 & 3,5 \\
\hline & Doğru malzeme & $\mathbf{0}$ & 0 \\
\hline & Doğru teknik ve & & \\
\hline & doğru malzeme & 27 & 31,8 \\
\hline Soru 17 & iki protez de başarılı & 58 & 69 \\
\hline & $\begin{array}{l}\text { Ikincisi başarılı } \\
\text { ikiz, }\end{array}$ & 19 & 22,6 \\
\hline & İki protez de başarısız & 7 & 8,3 \\
\hline Soru 18 & Evet & 50 & 58,8 \\
\hline & Hayır & 35 & 41,2 \\
\hline Soru 19a & Evet & 47 & 55,3 \\
\hline & Hayır & 38 & 44,7 \\
\hline Soru 19b & Evet & 40 & 47,1 \\
\hline & Hayır & 45 & 52,9 \\
\hline Soru 20a & Evet & 9 & 10,6 \\
\hline & Hayır & 76 & 89,4 \\
\hline Soru $20 \mathrm{~b}$ & Evet & 81 & 95,3 \\
\hline & Hayır & 4 & 4,7 \\
\hline
\end{tabular}

\begin{tabular}{llrl} 
Soru 21 & Evet & 61 & 70,9 \\
& Hayır & 23 & 26,7 \\
Soru 22a & Evet & 40 & 47,1 \\
& Hayır & 45 & 53,9 \\
Soru 22b & Evet & 76 & 89,4 \\
& Hayır & 9 & 10,6 \\
\hline
\end{tabular}

Ankete katılan öğrencilerin \%4,7'si 3.Sınıfta tam protezde dişli prova için 1 seans, $\% 11,8^{\prime} i$ 2 seans, $\% 21,2$ 'si 3 seans ve $\% 62,4$ 'ü 4 ve daha fazla seans harcadığını belirtmiştir. Ankete katılan öğrencilerin $\% 16,5^{\prime} \mathrm{i}$ 5.Sınıfta tam protezde dişli prova için 1 seans, $\% 31,8^{\prime i} 2$ seans, \%21,2'si 3 seans ve $\% 30,6$ 's 4 ve daha fazla seans harcadığını belirtmiştir.

Ankete katılan öğrencilerin $\% 63,5^{\prime} i \quad 3 . S$ snıfta tam protezin uyumlandırımasında zorlandığını, $\% 36,5^{\prime} \mathrm{i}$ uyumlandırılmasında zorlanmadığını belirtmiştir. Ankete katılan öğrencilerin \%34,1'i 5.Sınıfta tam protezin uyumlandırılmasında zorlandığını, $\% 65,9$ 'u uyulmandırımasında zorlanmadığını belirtmiş̧tir.

Ankete katılan öğrencilerin \% 84,7'si 3. Sınıfta iken tam protez yapmış olmanın eğitimlerine katkı sağladığını, \%15,3'ü katkı sağlamadığını belirtmiştir.

Anket sonuçlarına göre öğrencilerin \%96,4'ü teorik eğitim tamamlanmadan pratik uygulamaya geçilmemesi gerektiğini düşünmektedir.

Ankete katılan öğrencilerin $\% 83,5^{\prime} \mathrm{i} 3$. ve 5 . Sınıfta tam protez yapımına ayırdığı seans sayısında veya saatte farkllık olduğunu, $\% 16,5^{\prime} i$ farkllık olmadığını belirtmiştir.

Ankete katılan öğrencilerin $\% 78,8^{\prime} \mathrm{i} 3$. ve 5 . Sınıfta tam protez yaparken kullandığı malzeme miktarında farklılık olduğunu, \%21,2'si farklılık olmadığını belirtmiştir.

Ankete katılan öğrencilerin \% 38,2'si Teorik bilgileri eksik iken görsel anlatım ile tedavi basamaklarıı tam olarak anladığını, \%61,8'si anlayamadığını belirtmiştir.

Ankete katılan öğrencilerin $\% 89,7$ 'si teorik bilgileri eksik iken görsel anlatım ile tedavi basamaklarıı tam olarak anlayamadığını, pratik yaptıkları zaman anladıklarını belirtmiştir.

Ankete katılan öğrencilerin $\% 15,6$ 'sı teorik ve pratik bilgileri tam iken görsel anlatım ile tedavi basamaklarını tam olarak anlayamadığını belirtmiştir. Ankete katılan öğrencilerin \%41,3'ü pratik bilgileri tam teorik bilgileri hiç yok iken sözlü anlatım ile tedavi basamaklarını anladığını belirtmiştir.

Ankete katılan öğrencilerin $\% 7,1^{\prime} \mathrm{i}$ pratik uygulama yapılmamış olsaydı derslerde öğretilen teorik 
bilgiden sonra tam protezi tek başına yapmak zorunda kaldıklarında, başarılı olabileceklerini, \%91,8'i başarılı olamayacaklarını düşündüklerini belirtmişlerdir.

Ankete katılan öğrencilerin \%30,6'sı mezun olduktan sonra karşılaşılabilinecek farklı problemlerde teorik bilgilerine dayanarak doğru tedavi planı yapabileceğini düşündüklerini, \%69,4'ü doğru tedavi planı yapamayacağını düşündüklerini belirtti.

Ankete katılan öğrencilerin \%69,4'ü 3. Sınıfta yaptıkları tam protezden hastalarının yeterince memnun kaldığını, \%30,6'sı hastalarının yeterince memnun kalmadığını belirtmiştir. Ankete katılan öğrencilerin \% 80'i 5.Sınıfta yaptıkları tam protezden hastalarının yeterince memnun kaldığını, \%20'si hastalarının yeterince memnun kalmadığını belirtmiştir.

Ankete katılan öğrencilerin hasta memnuniyetsizliğinin \% 90'ı vuruk şikayetleri, \%33,8'i protezin ağızda durmaması, \% 21'i yemek sırasında kullanamama ve \%3,7si eklem rahatsızlıkları nedeni ile olduğunu bildirmişlerdir.

Ankete katılan öğrencilerin $\% 64,7$ 'si tam protezlerin başarısının hekim tecrübesine ve doğru teknik uygulamaya, \%3,5'i hekim tecrübesine, \%31,8'i ise doğru teknik ve doğru malzeme kullanımına bağlı olduğunu düşündüklerini belirtmiştir.

Ankete katılan öğrencilerin \% 69'u hem pratik eğitim ile hem de teorik ve pratik eğitimi tamamladıktan sonra yaptıkları protezlerde başarılı olduklarını $\% 22,6$ 'sı ilk protezlerinin başarısız ikinci protezlerinde başarılı olduklarını, \%8,3'ü iki protezde de başarısız olduklarını belirtmişlerdir Ankete katılan öğrencilerin \%46'sı başarısızlıklarının sebebinin bilgi ve deneyim eksikliği, \% 11'i bilgi eksiliği, \% 53'ü deneyim eksikliği olduğunu düşündüklerini belirtmiştir.

Ankete katılan öğrencilerin $\% 58,8^{\prime} i$ dişli provada dikkat edilmesi gereken kuralları teorik olarak bildiklerini ve ilgili bilgileri pratikte uygulayabildiklerini, $\%$ 41,2'si ise uygulayamadıklarını belirtmiştir.

Ankete katılan öğrencilerin \%55,3'ü 5. Sınıfta tam protez yaparken her aşamada daha tecrübeli birinin onayına gerek duyduklarını, \%44,7'si gerek duymadıklarını belirtmiştir. Ankete katılan öğrencilerin \% 47,1'i kendilerinin doğru yaptıklarına karar verebildiğini, \%52,9'u karar veremediğini belirtmiştir.

Ankete katılan öğrencilerin \% 10,6'sı teorik bilgilerin her vakada aynen geçerli olmak zorunda olduğunu, \%89,4'ü teorik bilgilerin her vakada aynen geçerli olmak zorunda olmadığını belirtmiştir.
Ankete katılan öğrencilerin \%95,3'ü pratikte vakaya göre değişiklik yapmak gerekebildiğini, \% 4,7'si pratikte vakaya göre değişiklik yapmak gerekmediğini düşündüklerini belirtmiştir.

Ankete katılan öğrencilerin \%72,6'sı 5. Sınıfta preprotetik tedavinin nasıl yapılacağını biliyor olduğunu belirtmiştir.

Ankete katılan öğrencilerin $\% 47,1^{\prime}$ i 3 . Sınıfta tam protez hastasının panoromik filmini tanımlayabildiğini, \%52,9'u tanımlayamadığını belirtmiştir. Ankete katılan öğrencilerin $\% 84,9$ 'u 5 . Sınıfta tam protez hastasının panoramik filmini tanımlayabildiğini, $\% 10,6$ 'sı tanımlayamadığını belirtmiştir.

\section{TARTIŞMA}

Tam protezlerde teorik ve pratik eğitimin öneminin değerlendirildiği çalışmamızda, öğrencilerin tamamı tam proteze teorik bilgiye sahip olunarak başlamanın tek başına yeterli olmadığını, teorik ve pratik bilginin ikisinin de olması gerektiğini ve teorik eğitimin tamamlanıp pratik uygulamaya geçilmesinin en verimli öğrenme şekli olduğunu belirtmişlerdir.

Sukotjo ve ark ${ }^{31}$ larının yaptığı bir araştırmaya göre, Harward Diş Hekimliiği Fakültesinde pratik saatlerinin diğer okullardan daha az olduğu ve bunun da öğrenciler üzerinde problem temelli eğitimin yetersiz olmasından dolayı anksieteye ve kendilerini yetersiz görmelerine neden olduğu ortaya çıkmıştır.

3. sınıfta tam protez pratik uygulamasında ölçü alırken uygulanan ağız hareketlerinin amacı, 1 . ve 2. ölçü alırken ölçünün doğru alınıp alınmadığına karar verebilme, protezde mum duvarlar ile oklüzal düzlem ve dikey boyutu doğru tespit edebilme oranı 5. sınıfta yapılan pratik uygulamaya kıyasla daha düşük olduğu ve 3.sınıfta tam protezin uyumlandırımasında 5. sınıfa göre daha fazla zorlanıldığı belirlenmiştir.

3.sınıfta tam protezde dişli prova için harcanılan zaman, protez yapımına ayrılan süre ve kullanılan malzeme miktarı daha fazladır. Buna karşılık 5. sınıfta pratik uygulama sonucu yapılan tam protezler daha başarılır.

Chicago'daki Illinois Üniversitesi Diş Hekimliği Koleji'nde geleneksel klinik öncesi tam protez müfredatı pasif dersler ve düşük kalitede laboratuvar egzersizlerini içerirken, ikinci sınıf öğrencileri için hastalarla klinikte aktif öğrenme şeklinde bir program uygulamaya karar vermişlerdir. Tamamen teknik/ labo-

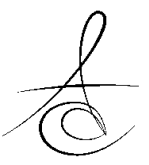


ratuvar açıdan hasta merkezli eğitim oluşturulmuştur. Obrez ve ark ${ }^{32 \prime l a r ı n ı n ~ y a p t ı g ̆ ı ~ a r a s ̧ t ı r m a y a ~ g o ̈ r e ~ g e l e-~}$ neksel programında olanlar ile yeni programdaki öğrencilerin final sınavı sonuçlarını karşılaştırıldığında yeni programdaki öğrencilerin toplam puanı istatistiksel olarak anlamlı bir iyileşme gösterdiği tespit edilmiştir.

Anket sonuçlarımıza göre öğrencilerin \%91,8'i pratik uygulama yapılmasaydı derslerde öğretilen teorik bilgiden sonra tam protezi tek başınıza yapmak zorunda kaldıklarında başarılı olamayacaklarını düşünmektedirler.

Öğrencilerin \%30,6'sı mezun olduktan sonra karşılaşabilecekleri ve okulda gördüklerinden farklı tam protez vakalarında ve farklı problemlerde teorik bilgilerine dayanarak doğru tedavi planı yapabileceğini, \%69,4'ü doğru tedavi planı yapamayacağını düşünmektedirler.

3. ve 5. sinıfta yapılan tam protezlerde hasta memnuniyetsizliğinin ortak sebebi çoktan aza doğru vuruk şikâyetleri, protezin ağızda durmaması, yemek sırasında kullanamama ve eklem rahatsızlıklarıdır. Şikayet yüzdelerinin 3. Sınıfta yapılan tam protez vakalarında daha fazla olduğu tespit edilmiştir. 5. Sınıfta öğrencilerin teorik bilgileri tamamlandıktan sonra tam protez yaparken her aşamada kendilerinden daha tecrübeli birinin onayına duyulan intiyaç azalmıştır.

Anket sonuçlarına göre 3. sınıfta yapılan tam protez çalışması sırasında öğrencilerin bilgi eksikliğinden kaynaklanan kaygı ve kendine güvensizlik ön plandadır. Hastaya yaklaşım ve vakayı inceleme, tam protez yapımının her aşaması tam bilinmemekle birlikte alınan yardımcı destekle başarılı işler elde edildiği belirlenmiştir. Ancak harcanılan zaman ve hasta için proteze sahip olma süresinin uzaması söz konusudur. Deneyim açısından bakıldığında ise öğrencilerin $\% 84,7$ 'si kendileri için yararlı bir uygulama yapıldığını düşünmektedir.

\section{SONUÇ}

Diş hekimliği eğitimi teorik ve pratik eğitimin birlikte verilmesi gereken bir ilim ve sanat dalıdır. Çalışmamızda, teorik eğitimin pratik eğitimle tamamlandığı zaman diş hekimleri öğrencilerinin kendilerini güvende hissettiği ve öğrencilerin bilgi eksikliğinden kaynaklanan kaygı ve kendine güvensizlik duygusunun gittikçe azaldığı tespit edilmiştir.

\section{KAYNAKLAR}

1. Çalıkkocaoğlu S. Dişsiz Hastaların Protetik Tedavisi Klasik Tam Protezler, 5. baskı, Quintessence Yayıncılık Ltd. Şti, İstanbul, 2010.

2. Davies SJ, Gray RMJ, McCord JF. Good occlusal practise in removable prosthodontics. $\mathrm{Br}$ Dent J 2001;191:491-502.

3. Kulak Özkan Y. Tam Protezler ve İmplantüstü Hareketli Protezler Problemler ve Çözüm Yolları 1. Cilt, 1. baskı, Vestiyer Yayın Grubu, İstanbul, 2012.

4. Beşparmak A. Postmenopozal Kadınlarda Osteoporozun Mandibula Üzerindeki Etkisi, İ.Ü. Diş Hekimliğ Fak. Doktora Tezi 1996.

5. Çalıkkocaoğlu S, Tam protezler. 3.Baskı. İstanbul. 1998

6. Kesercioğlu A, Ulusoy M, Saraçoğlu A. Protetik Diş Tedavisinde İlkeler ve Uygulamalar, E.Ü Diş Hekimliği Dergisi, 1997; 97-112.

7. Hayakawa I. Total Protezlerin Temel İlkeleri ve Pratiği, Protezlerin Zihinde Canlandırıması. Kazazoğlu E. İstanbul 2007.

8. Atasever N, Çekiç C. Tam Protez Hastalarında Protez Şikayetlerinin Diagnostik Önemi, Hacettepe Üniversitesi Diş Hekimliği Fakültesi Dergisi 1997; 11: $16-9$.

9. Akçabay C. Ölçü Maddeleri ve Klinik Uygulamaları, G.Ü Fakültesi, Ankara, 1993, s:47-49.

10. Dawson PE. Evaluation, Diagnosis and Treatment of Occlusal Problems, St. Louis: The C.V. Mosby Company, 1989; 56-72.

11. Fayz F, Eslomi A. Determination of Occlusal Vertical Dimension: A literature review.J Prosthet Dent 1988; 59: 321-3.

12. Kaplan RL. Concepts of occlusion and gnathology. Dent Clin North Am 1963; 557-90.

13. Köylüoğlu A.Ö. Yeni terimler ve tanımlar ile okluzyon teorileri. İzmir: 1985. s:5-16.

14. Okeson JF. Management of Temporomandibular Disorders and Occlusion. 4th ed. Mosby St.Louis 1998; 87-104.

15. Mohamed A, El-Aramany MA, George WA, Scott $\mathrm{RH}$. Evaluation of the needle point tracing as a method for determining centric relation. J Prosthet Dent 1965;1043-54.

16. Keshvad A, Winstanley RB. An appraisal of the literature on centric relation. Part $1 \mathrm{~J}$ Oral Rehabil 2000; 27. 
17. Smith HA. Comparison of Empirical Centric Relation Records With Location of Terminal Hinge Axis and Apex of The Gothic Arc Tracing. J Prosthet Dent 1975; 511-20.

18. Glossary of Prosthodontic Terms J Prosthet.Dent 1999; 81:71.

19. Ebner KA, Otis LL, Zakhary R, Danforth RA. Axial Temporomandibular Joint Morphology, Oral Surg Oral Med Oral Pathol 1990; 69: 247-8.

20. Carvalho OT. A New Fully Adjustable Articulator System and Procedure. J Prosthet Dent 1998; 80: 376-86.

21. Squier RS. Jaw Relation Records for Prosthodontics. Dent Clin North Am 2004; 48: 47186.

22. Palik JF, Nelson Dr, White JT. Accuracy of an Earpiece Face-bow. J Prosthet Dent 1985; 53:8004.

23. Nagy WW, Smithy TJ, With CG. Accuracy of Predetermined Transverse Horizontal Mandibular Axis Point. J Prosthet Dent 2002; 87: 387-94.

24. Shillinburg HT, Hobo S, Whitssatt L.D. Fundamentals of Fixed Prosthodontics. 3rd. ed. Chicago, Quintessence Pub. Co;1996; 29.

25. Farias-Neto A, Dias AH, de Miranda BF, de Oliveira AR. J Oral Rehabil 2013; 40:686-92.

26. Baily LR. Recording Edentulous Jaw Relationships. Dent Clin North Am 1977; 21:271-83.

27. Esposito SJ. Esthetics For Denture Patients. J Prosthet Dent 1980; 44: 608-15.

28. Kern BE. Anteropometric Parameters of Tooth Selection, J Prosthet Dent 1997; 17: 431-7.

29. Isa ZM, Abdulhadi LM. Relationship of maxillary incisors in complete dentures to the incisive papilla. J Oral Sci 2012; 54:159-63.

30. el-Gheriani AS. A new guide for positioning of maxillary posterior denture teeth. J Oral Rehabil 1992; 19(5):535.

31. Sukotjo C, Thammasitboon K, Howell H, Karimbux N. Students' perceptions of prosthodontics in a PBL hybrid curriculum. J Prosthodont 2008; 17: 495501.

32. Obrez A, Lee DJ, Organ-Boshes A, Yuan JC, Knight GW. A clinically oriented complete denture program for second-year dental students. J Dent Educ 2009; 73: 1194-201.

\section{Yazışma Adresi}

Dr. Ş. Begüm Türker

Marmara Üniversitesi

Diş Hekimliği Fakültesi

34854 Başıbüyük, Maltepe

İstanbul, Türkiye

Tel: 02164121621 (1777)

Fax: 02164210291

e-mail: begumturker@hotmail.com 